\title{
A FORMAÇÃO DE PROFESSORES INDÍGENAS E A OFERTA DE CURSOS NO CEFORR EM RORAIMA
}

\section{ARTIGO ORIGINAL}

FEITOZA, Sâmella Kalyne Araújo ${ }^{1}$

VASCONCELOS, Vanessa Rufino Vale ${ }^{2}$

LIRA, Lysne Nôzenir de Lima ${ }^{3}$

MATOS, Maristela Bortolon de ${ }^{4}$

FEITOZA, Sâmella Kalyne Araújo. Et al. A formação de professores indígenas e a oferta de cursos no CEFORR em Roraima. Revista Científica Multidisciplinar Núcleo do Conhecimento. Ano 05, Ed. 02, Vol. 03, pp. 05-30. Fevereiro de 2020. ISSN: 24480959, Link de acesso: https://www.nucleodoconhecimento.com.br/educacao/professores-indigenas

\section{RESUMO}

Este artigo apresenta resultados de um estudo cujo objetivo foi compreender como é ofertada a formação dos professores indígenas pelo Centro Estadual de Formação dos profissionais da Educação de Roraima (CEFORR). O estudo consiste em uma pesquisa documental. Essa instituição possui três cursos voltados para a formação inicial em magistério dos professores indígenas, o curso Tamîkan, o Amooko lisandan e o Yarapiari; e ainda possui um curso de formação continuada, o Murumurutá, que tem como objetivo o aprimoramento do conhecimento da língua materna. A análise das fontes permitiu constatar que tais conquistas educacionais para os povos

\footnotetext{
${ }^{1}$ Mestranda em Educação.

${ }^{2}$ Mestranda em Educação.

${ }^{3}$ Mestranda em Educação.

${ }^{4}$ Doutora em Educação.
} 
indígenas vieram precedidas de um processo de reivindicação e lutas. Também se pôde compreender que a construção do conhecimento está para além de uma educação pautada na manutenção das tradições e costumes, busca-se por meio da formação ofertar uma educação que atenda às especificidades dos povos indígenas, conciliando-as aos conhecimentos científicos.

Palavras-chave: CEFORR, educação escolar indígena, formação de professores.

\section{INTRODUÇÃO}

Com a menor densidade demográfica do Brasil, Roraima possui proporcionalmente, de acordo com o Censo do IBGE (2010), a maior população indígena do país, pois 55.922 (cinquenta e cinco mil e novecentos e vinte e duas) pessoas se declaram ou se consideram indígenas em Roraima. Assim, 49.637 (quarenta e nove mil seiscentos e trinta e sete) pessoas se declaram indígenas usando o quesito cor ou raça e 6.285 (seis mil duzentos e oitenta e cinco) não se declararam, mas se consideram indígenas. O território possui 32 (trinta e duas) terras indígenas ocupadas pelos povos: Macuxi, Wapichana, Taurepang, Wai-Wai, Yanomami, Waimiri Atroari, Patamona, Yekuana, Ingaricó, sendo que os povos Macuxi são a maioria da população indígena do estado (IBGE, 2010)

Outra singularidade de Roraima é que, conforme o Censo Escolar de 2018, das 839 (oitocentas e trinta e nove) escolas, somadas aqui as redes federal, estadual, municipal e privada, apenas 283 (duzentas e oitenta e três) instituições de ensino, isto é, 34\%, estão localizadas em área urbana e 556 (quinhentos e cinquenta e seis), que representam $66 \%$, em área rural, ou seja, o estado possui mais unidades de ensino em área rural do que em área urbana. Porém, como a maioria da população reside nas zonas urbanas, a população matriculada nas escolas, incluindo todas as modalidades e etapas de ensino, somam 156.855 matrículas, sendo que na zona rural representam 38.653 (trinta e oito mil, seiscentos e cinquenta e três) matrículas e de 118.202 (cento e dezoito mil e duzentos e dois) na zona urbana (INEP, 2018). 
Do total de 556 (quinhentos e cinquenta e seis) escolas localizadas na zona rural, 383 (trezentos e oitenta e três) são indígenas, representando $68,9 \%$ do total de escolas rurais, e possuem 21.569 (vinte e um mil, quinhentos e sessenta e nove) alunos matriculados, sendo o maior número destes matriculados no Ensino Fundamental, representando 69,5\% das matrículas de alunos indígenas (INEP, 2018).

Sobre a educação escolar indígena, analisando o Censo Escolar 2018, aferimos que a rede estadual de ensino possui 15.902 alunos, o que representa $73,7 \%$ do total de alunos indígenas da rede básica. Temos quatro municípios em que todas as instituições de ensino estadual que estão localizadas na zona rural são indígenas, são eles: Uiramutã, Normandia, Pacaraima e São João da Baliza, sendo que os três primeiros são os municípios que mais possuem alunos indígenas. Já os municípios de Rorainópolis e São Luiz não possuem alunos indígenas na rede estadual de ensino (INEP, 2018).

Diante dessa realidade, ressaltamos a importância da oferta de uma educação que contemple a diversidade cultural, pois a escola é um espaço de convivência de diversas culturas e toda prática pedagógica envolve questões culturais. Nesse sentido, Candau (2008, p. 13) afirma que "[...] não é possível conceber uma experiência pedagógica 'desculturizada', isto é, desvinculada totalmente, das questões culturais da sociedade".

Considerando essa realidade do sistema escolar, buscamos compreender como é ofertada a formação dos professores indígenas em Roraima, no âmbito estadual, realizada pelo Centro Estadual de Formação dos Profissionais da Educação de Roraima (CEFORR). Para alcançar o objetivo proposto, realizamos um estudo documental com base nos Projetos Políticos Pedagógicos dos Cursos voltados para a formação de professores indígenas do CEFORR. Além disso, recorremos a legislações educacionais vigentes, com ênfase na Lei de Diretrizes e Bases da Educação, Lei no 9.394/1996, e na Resolução CEB/CNE no 3 de 1999.

Este artigo aborda, inicialmente, a formação de professores indígenas em âmbito nacional destacando o processo de implantação de políticas públicas na área da 
educação para os povos indígenas e, posteriormente, focaliza a formação dos professores indígenas no estado de Roraima pelo Centro Estadual de Formação dos Profissionais da Educação de Roraima (CEFORR), apresentando os cursos atualmente ofertados para a formação de professores indígenas, quais grupos indígenas são atendidos. Por fim, apresenta o impacto positivo dessa formação para o fortalecimento da língua materna e da cultura dos povos atendidos, ao tempo em que aponta algumas necessidades para o fortalecimento da qualidade do ensino indígena no estado de Roraima.

\section{MARCOS HISTÓRICOS E LEGAIS DA EDUCAÇÃO ESCOLAR INDÍGENA NO BRASIL}

O percurso histórico da educação da população indígena, inicialmente na forma não escolarizada, conforme David, Melo e Malheiro (2013), teve início em 1549, com a chegada dos Jesuítas. Essa educação tinha como finalidade a catequese, a domesticação e a escravização dos índios.

A educação escolar para indígenas no Brasil inicia-se em 1910, com a criação do Serviço de Proteção do Índio e Localização dos Trabalhadores Nacionais (SPILTN posteriormente denominada SPI), pelo Decreto o 8.072, que tinha como um de seus objetivos ministrar, sem obrigatoriedade, instrução primária e profissional aos povos indígenas. Em 1967, em substituição ao SPI, foi criada a Fundação Nacional do Índio (FUNAI), pela Lei no 5.371 , de 5 de dezembro de 1967 responsável pela criação de uma rede em escolas bilíngues, com a prática da língua e das tradições indígenas, e da contratação dos primeiros professores indígenas. No entanto, convém frisar que, a educação dessa população sempre sofreu a imposição cultural do não índio.

Em 1973, aprovou-se o Estatuto do Índio, por meio da Lei n ${ }^{\circ}$ 6.001, de 19 de dezembro de 1973, legislação essa ainda em vigor. O Art. 50 dessa lei, ao tratar da educação escolar indígena, instituiu: "A educação do índio será orientada para a integração na comunhão nacional mediante processo de gradativa compreensão dos problemas gerais e valores da sociedade nacional bem como do aproveitamento das suas aptidões individuais". 
Posteriormente, surgiram os movimentos de lutas encabeçadas por instituições não governamentais, universidades e estudiosos do tema, resultando nas garantias estabelecidas pela Constituição da República Federativa do Brasil (CF), promulgada em 5 de outubro de 1988, que, discorrendo sobre a educação, no artigo 205, estabelece:

A educação, direito de todos e dever do Estado e da Família, será promovida e incentivada com a colaboração da sociedade, visando ao pleno desenvolvimento da pessoa, seu preparo para o exercício da cidadania e sua qualificação para o trabalho. (BRASIL, 1988, p.123).

Quanto aos direitos dos povos indígenas, a CF/1988 estabelece, especificamente no artigo 231, que "São reconhecidos aos índios suas organizações sociais, costumes, língua, crenças e tradições, e os direitos originários sobre as terras que tradicionalmente ocupam, competindo à União, demarcá-las, proteger e fazer respeitar todos seus bens" (BRASIL, 1988, p. 133).

A Constituição assegura a todos os povos o respeito pelo seu modo de ser, viver e de se organizar socialmente, repercutindo positivamente na educação escolar das comunidades tradicionais, como podemos visualizar no artigo 210 que, ao discorrer sobre a educação, garante a utilização pelos povos indígenas de sua língua materna:

Art. 210. Serão fixados conteúdos mínimos para o ensino fundamental, de maneira a assegurar formação básica comum e respeito aos valores culturais e artísticos, nacionais e regionais.

$[\ldots]$

$\S 2^{\circ}$ O ensino fundamental regular será ministrado em língua portuguesa assegurada às comunidades indígenas também a utilização de suas línguas maternas e processos próprios de aprendizagem. (BRASIL,1988, p. 124). 
Em 1991, foi instituído o Decreto Presidencial № 26/1991, que atribuiu competência ao Ministério da Educação de integrar a educação escolar indígena ao sistema de ensino regular, além de coordenar ações em todos os níveis e modalidades de ensino, delegando competências aos estados e municípios para assumirem as escolas que antes estavam sob a gerência da FUNAl.

Apesar dos avanços, foi apenas em 1996, com o surgimento da Lei de Diretrizes e Bases da Educação (LDB), que foi garantido aos povos indígenas o direito a uma educação escolar específica, diferenciada e bilíngue, que respeitasse sua cultura, sua forma de construir e transmitir conhecimento, com currículos construídos a partir das especificidades de cada comunidade indígena e elaborados por estas. A LDB.

Quanto à organização escolar indígena, o artigo 79 da LDB estabelece:

$\S 2^{\circ}$ Os programas a que se refere este artigo, incluídos nos Planos Nacionais de Educação, terão os seguintes objetivos:

I - fortalecer as práticas sócio-culturais e a língua materna de cada comunidade indígena;

II - manter programas de formação de pessoal especializado, destinado à educação escolar nas comunidades indígenas;

III - desenvolver currículos e programas específicos, neles incluindo os conteúdos culturais correspondentes às respectivas comunidades;

IV - elaborar e publicar sistematicamente material didático específico e diferenciado. (BRASIL, 1996).

Nesse percurso, surgiu, em 1998, o Referencial Curricular Nacional para as Escolas Indígenas, que apresenta os fundamentos da educação escolar indígena e orientações didáticas quanto à prática curricular que resultem nas ações de implementação e desenvolvimento dos Projetos Pedagógicos das Escolas Indígenas. 
Outra relevante conquista para os povos indígenas foi a aprovação da Resolução CNE/CEB no 03/1999, a qual institui, no âmbito da Educação Básica, a estrutura e funcionamento das Escolas Indígenas e fixando as Diretrizes Curriculares do Ensino Intercultural e Bilíngue, objetivando a valorização plena das culturas dos Povos Indígenas. Essa resolução determina ainda que os professores das escolas indígenas, prioritariamente, sejam membros de suas próprias comunidades. $\mathrm{O}$ artigo $7^{\circ}$ desse documento delibera aos cursos de formação de professores indígenas destaque à composição de competências referenciadas em conhecimentos, valores, habilidades e atitudes, na elaboração e no desenvolvimento dos currículos valorizando a cultura e os saberes indígenas.

O Parecer CNE/CEB № 14/1999, aprovado em 14 de setembro, normatiza as Diretrizes Curriculares Nacionais para o funcionamento das escolas indígenas. Em novembro desse mesmo ano, essas diretrizes são fixadas por meio da Resolução no 03/1999. Em seu Art. 1ํ, resolve:

Estabelecer, no âmbito da educação básica, a estrutura e o funcionamento das Escolas Indígenas, reconhecendo-Ihes a condição de escolas com normas e ordenamento jurídico próprios, e fixando as diretrizes curriculares do ensino intercultural e bilíngue, visando à valorização plena das culturas dos povos indígenas e à afirmação e manutenção de sua diversidade étnica. (BRASIL, 1999)

Devemos destacar que nesse período, conforme apontam David, Melo e Malheiro (2013, p. 114) "muitos índios davam aulas de $1^{\text {a }}$ a $4^{\mathrm{a}}$ séries sem a formação exigida pelas leis que regem o sistema regular de ensino brasileiro". Houve então um direcionamento para que esses professores indígenas finalizassem o ensino fundamental, e, posteriormente, seguissem para o ensino médio, de modo a obter habilitação para o magistério.

Assim, em 1999, surgiram os magistérios indígenas, modalidade autorizada pela Câmara de Educação Básica (CEB), que, em suas diretrizes, estabeleceu que as aulas deveriam acontecer no período de recesso escolar das comunidades indígenas, 
para não interromper o período letivo. Tal ação progrediu, em meados dos anos 2000, para a formação de professores indígenas por meio de curso superior.

Em Roraima a legislação em vigor que garante aos povos indígenas o direito à educação escolar indígena é o Parecer do Conselho Estadual de Educação (CEE/RR) no 19/2004, que instituiu as Diretrizes Curriculares do Curso de Magistério Indígena, fundamentado na Convenção no 169 da Organização Internacional do Trabalho (OIT). Esse instrumento objetiva garantir a esses povos os direitos mínimos de salvaguardar suas culturas e sua identidade no contexto das sociedades que integram.

No ano de 2012, foi deliberada, pela Câmara de Educação Básica do Conselho Nacional de Educação, da Resolução ㄲo 5, que define as diretrizes curriculares nacionais para a educação escolar indígena. O Art. 20, apresenta que a formação de professores e gestores indígenas deve ser prioridade de suas instituições formadoras, a fim de ser consolidada a Educação Escolar Indígena. Ademais, a formação inicial desses professores "[...] deve ocorrer em cursos específicos de licenciaturas e pedagogias interculturais [...] a formação inicial será ofertada em serviço [...] concomitante com a própria escolarização" (BRASIL, 2012, p. 10). Apresenta ainda que as instituições formadoras devem garantir o acesso, a permanência e o êxito, visando a uma formação sociocultural de qualidade.

Acatando a determinação da LDB homologa-se o atual Plano Nacional de Educação (PNE), pela Lei ํㅜ 13.005/2014, válido para o decênio 2014/2024, No inciso II do $\S 1^{\circ}$ do artigo 8 , deverão constar em seus planos estratégias que "II - considerem as necessidades específicas das populações do campo e das comunidades indígenas e quilombolas, asseguradas a equidade educacional e a diversidade cultural" (BRASIL, 2014, p. 01).

Acompanhando o Plano Nacional de Educação (PNE), que busca combater as desigualdades educacionais, alinhando os sistemas de ensino de todos os entes federativos, no Estado de Roraima foi aprovada a Lei Estadual no $1.008 / 2015$, que estabelece o Plano Estadual de Educação (PEE), para o período de 2014 a 2024. Sobre a formação de professores indígenas, destaca como meta: 
9.16 - assegurar, a partir da vigência deste plano, políticas de formação continuada para professores, gestores e profissionais de apoio, em todas as áreas de conhecimento, em atendimento a todos os níveis e modalidades de ensino, por meio de projetos societários e identitários de suas comunidades;

9.24 - regulamentar, no Sistema Estadual de Ensino, a profissionalização e o reconhecimento do magistério indígena com a categoria de professor indígena como carreira específica, considerando as particularidades linguísticas e socioculturais que lhe são próprias. (RORAIMA, 2015).

Ressaltamos aqui que todo o processo de conquistas dos povos indígenas relacionadas à educação esteve precedido por lutas, assim como em qualquer outro âmbito. Tais lutas é que viabilizaram a garantia dos direitos por meio de documentos legais. Instituídos os direitos, estes passam a ser supervisionados e acompanhados por esses povos, demonstrando assim o papel de comunidade cidadã, que fiscaliza com forte representação e que busca aliar os conhecimentos científicos às especificidades culturais das suas comunidades.

A trajetória dos Povos Indígenas no estado de Roraima, salienta Souza (2016), está marcada por lutas, resistências e reinvindicações de direitos, dentre essas destacase a ocorrida na década de 1980, onde lideranças indígenas, uniram-se e fortaleceram os conselhos e organizações indígenas, buscando soluções de seus problemas, em prol do bem comum de todos os povos indígenas, independentemente de sua etnia.

Essas deliberações até aqui apresentadas comprovam a relevância das organizações indígenas para a defesa da manutenção de sua cultura, identidade e língua a partir das mobilizações e reivindicações de seus direitos, sobretudo quanto ao acesso e à permanência à/na formação escolar indígena no estado de Roraima. O processo de lutas desses povos resultou em conquistas importantes para a efetivação de leis e políticas públicas, tornando-se capazes de atendê-los em suas necessidades e especificidades. 
Como vimos, a educação escolar indígena deve considerar as particularidades de cada povo. A língua materna é, por exemplo, um dos componentes mais importantes da cultura dos povos indígenas, por isso a imprescindibilidade de sua valorização e manutenção. Dessa forma, para compreendermos a formação de professores indígenas, é importante frisar também a especificidade da educação escolar indígena. O Ministério da Educação, em publicação intitulada O Governo brasileiro e a educação escolar indígena (1998), salienta que a educação indígena deve ser "específica e diferenciada", pois:

[...] são portadoras de tradições culturais singulares e vivenciaram processos históricos distintos. Cada um desses povos é único, tem uma identidade própria, fundada na própria língua, no território habitado e explorado, nas tradições, costumes, história e organização social. Para que os direitos dos povos indígenas à diferença permaneçam resguardados é necessário que as escolas indígenas sejam específicas e diferenciadas das escolas oferecidas aos não-índios e que envolvam a comunidade indígena como agente e co-autora dos processos por ela instituídos. (BRASIL, 1998, p. 13-14).

A formação de professores indígenas foi expandida devido à diversidade e às peculiaridades encontradas em cada comunidade, justificando assim a necessidade de que cada comunidade forme os seus próprios mestres, aqueles que atuarão na educação em sua comunidade para além do ensino escolarizado. Isto é, cabe a eles a tarefa de manter acesas as tradições do seu povo, juntamente com os anciãos de sua comunidade, preservando sua cultura, suas tradições e sua língua materna.

Após apresentado o caminho das políticas públicas que visam a garantir a educação escolar indígenas dentro de suas especificidades e também a atender à formação desse profissional que trabalhará na sua comunidade, apresentaremos os caminhos trilhados pela formação dos professores indígenas. 


\section{A FORMAÇÃO DE PROFESSORES INDÍGENAS}

A formação de professores indígenas, com vistas a atuar nas escolas indígenas no Brasil, teve início na Amazônia na década de 1980, tomando maiores proporções em 1990, como apresenta Grupioni (2013). Com isso, foi se percebendo a necessidade de elaboração de políticas públicas educacionais diferenciadas à população indígena, rompendo-se com a velha escola para o índio e implantando-se um novo modelo onde os docentes passaram a ser escolhidos pela própria comunidade, valorizando assim a língua, a cultura e o povo da comunidade.

As Diretrizes para a Política Nacional de Educação Escolar Indígena (1993) estabeleceram como provisória a atuação de professores não índios, tornando exclusiva a docência nas comunidades indígenas por professores indígenas. Esse documento propõe uma educação diferenciada, idealizada por movimentos indígenas e de luta pela terra, educação essa que valoriza os conhecimentos e saberes tradicionais, bem como a língua materna.

No início dos anos 2000, segundo David, Melo e Malheiro (2013), surgiram, no país, os primeiros cursos de licenciatura indígena, o primeiro na Universidade do Estado do Mato Grosso (UNEMAT), em julho de 2001, e o segundo na Universidade Federal de Roraima (UFRR), com o Núcleo Insikiran, em dezembro de 2001, agora Instituto Insikiran de Formação Superior Indígena. Ou seja, datam desse período os primeiros casos de ingresso da população indígena nos cursos de graduação voltados para a formação de professores indígenas, com o objetivo de atender à demanda de docentes nas escolas indígenas. $O$ ingresso dos povos indígenas em cursos de graduação foi progredindo a partir de 2003, em razão do estabelecimento do sistema de cotas em processos vestibulares.

Quanto formação inicial e continuada de professores indígenas, conforme preconizam os Referenciais para a Formação de Professores Indígenas (2002), é de competência das Secretarias Estaduais de Educação. Tal documento propõe que os cursos de formação inicial tenham duração entre 04 e 05 anos, com 02 módulos presenciais ao ano e de caráter multiétnico. 
Os futuros professores selecionados pelas lideranças indígenas para participar dos cursos de formação, por sua vez, devem possuir certas competências a fim de atender às demandas da realidade educacional das escolas indígenas. Ou seja,

Espera-se, entre outras competências, que o professor indígena seja um profundo conhecedor da história e das práticas culturais de seu grupo; que seja capaz de pesquisar e sistematizar conhecimentos; que tenha interesse e conhecimento por sua língua materna, de modo a ser capaz de compreender sua estrutura e a gerar materiais para seu estudo em sala de aula; que exerça o papel de mediador e articulador de informações entre sua comunidade, a escola e a sociedade envolvente; que seja capaz de propor uma organização curricular que oriente o trabalho a ser desenvolvido na escola, sequenciando conhecimentos e habilidades que seus alunos irão desenvolver. (GRUPIONI, 2013, p. 74).

Essas competências devem ser consideradas quando da seleção por parte da comunidade, daqueles que serão enviados para participar da formação em nível de magistério ou em um curso de graduação.

Em 2002, o Ministério da Educação e Cultura criou o Programa Diversidade na Universidade, com o objetivo de elaborar e implementar políticas públicas para o acesso ao ensino superior das populações afrodescendentes e indígenas, iniciando sua execução no ano de 2003. David, Melo e Malheiro (2013) apresentam que, posteriormente, o Programa Diversidade voltou seus esforços para melhorar a educação básica, e, desse modo, foi criado o Programa de Apoio à Formação Superior e Licenciaturas Indígenas (PROLIND), responsável por financiar as Licenciaturas Interculturais Indígenas, lançando em 2005 seu primeiro edital, com a oferta do curso em oito universidades, com habilitações em Línguas, Literatura e Arte, Ciências da Natureza e Matemática, Ciências Sociais e Humanidades.

Também no âmbito do Ministério da Educação (MEC), foi criada a Secretaria de Educação Continuada, Alfabetização e Diversidade (SECAD) em 2004, vindo a tornarse Secretaria de Educação Continuada, Alfabetização, Diversidade e Inclusão 
(SECADI) em 2011, todavia extinta em 2019. Na composição desse órgão estava a Coordenação Geral de Educação Escolar Indígena (CGEEI), responsável pela implantação e manutenção dos cursos, responsabilizando-se ainda pelos custos de hospedagem e alimentação dos indígenas nos períodos das aulas presenciais, via Governo Federal.

Tais iniciativas voltadas à educação escolar indígena impõem novos sentidos para a escolarização. Abbonizio e Ghanen (2016) apresentam ainda os aspectos que diferenciam a educação escolar indígena da escolarização convencional, que são:

A participação da comunidade na definição dos projetos educacionais e na escolha do professor ou professora; a elaboração de materiais didáticos a partir da realidade e necessidades comunitárias, com grande atenção à questão linguística; a predisposição para que o ensino e a aprendizagem se realizem a partir de atividades de pesquisa, vinculada à noção de que docentes são pesquisadores(as); enfim, a pretensão de que a escola contribua para a realização de projetos comunitários de futuro. (ABBONIZIO; GHANEN, 2016, p. 890).

As comunidades indígenas têm procurado estabelecer uma relação comunidadeescola de aproximação e pertencimento, o que tem sido indicado como um dos papeis sociais da escola. O movimento realizado pela população indígena chamou para si a responsabilidade pelo processo de formação escolar em sua comunidade. Dessa forma, os professores deslocam-se para consolidarem uma formação essencial a fim de desempenharem o magistério em suas comunidades. Nesse sentido, Silva (1999) defende que a escola,

[...] na mão dos próprios povos indígenas - [é] um instrumento decisivo na reconstrução e na afirmação das identidades. O desafio que se coloca é o de pensar as escolas indígenas em seus limites e suas possibilidades, dentro da realidade atual, cada dia mais norteada por tendências homogeneizadoras e globalizantes. (SILVA, 1999, p. 64). 
As escolas indígenas são um "instrumento de afirmação e reelaboração cultural", afirma Silva (1999, p. 66), ao tratar a respeito do movimento - e de sua importância para a construção de uma política de educação escolar indígena iniciada pelos estados do Acre, Amazonas e Roraima. Tal movimento consiste no deslocamento de uma visão de escola para índios para a construção de espaços políticos-educacionais, na busca por novas relações interculturais.

No Estado de Roraima, a educação indígena apresenta diversas peculiaridades, pois está inserida no processo educativo uma parcela da população que vive distante dos centros urbanos e luta diariamente pela manutenção das suas tradições culturais.

Quanto a atuação de professores nas comunidades indígenas em Roraima, atualmente as lideranças indígenas dão prioridade à seleção de professores indígenas, da própria comunidade e previamente selecionados por eles para participarem de cursos de formação na "cidade". Em alguns casos, professores não índios são autorizados a ministrarem aulas em suas comunidades, desde que atendam às especificidades da educação escolar indígena, onde a escola torna-se meio para o fortalecimento da cultura, da língua, das tradições e dos dogmas daquele povo.

A escola, assim, torna-se um espaço social de fortalecimento da cultura, da língua e do respeito aos conhecimentos culturalmente estabelecidos. Torna-se também espaço para a realização de reuniões, visando a tomadas de decisões, num processo de escuta onde todos têm direito a opinar, a questionar e a tirar dúvidas. Torna-se ainda local de construção de valores e consolidação cultural, onde os mais jovens recebem instruções, suas missões; onde, em colaboração, professor e ancião, instruem os alunos em conhecimentos considerados por eles relevantes e que estejam em consonância com sua cultura, para além dos conteúdos científicos.

Daí a relevância de se abordar a formação que vem sendo oportunizada aos professores indígenas no estado de Roraima, no sentido de apropriação de ferramentas que contribuam para a construção de espaços do fazer pedagógico, do 
conhecimento, da formação política, considerando sempre a importância do fortalecimento de suas tradições e costumes.

\section{A FORMAÇÃO DE PROFESSORES INDÍGENAS PELO CEFORR}

O Centro Estadual de Formação dos Profissionais da Educação de Roraima (CEFORR) é uma instituição subordinada à Secretaria de Educação e Desporto do Estado de Roraima (SEED). Foi criado no ano de 2007 e com o objetivo de realizar a formação, coordenar e acompanhar a execução dos programas federais de formação inicial em nível médio (magistério e profissionalizante) e continuada dos profissionais da educação, assim como da modalidade de Educação Escolar Indígena (RORAIMA, 2011).

Os cursos ofertados pelo CEFORR estão alinhados com o Plano Nacional de Educação (PNE) e com o Plano Estadual de Educação (PEE). As demandas para novos cursos podem surgir por meio de solicitações da SEED, das escolas, dos profissionais da educação estadual e municipal do estado de Roraima e por representantes da sociedade civil organizada.

Vale destacar que cada povo indígena é autônomo e manifesta-se culturalmente de maneira diferenciada. No entanto, quando abordam assuntos ou necessidades referentes à educação e à saúde, todos os povos se unem, esquecendo assim suas diferenças culturais, para, fortalecidos, lutarem em benefício de todos (RORAIMA, 2011).

Os cursos do CEFORR ofertados aos povos indígenas são coordenados pela Gerência de Formação Indígena (GFI), que tem à frente uma professora indígena, indicada em 16 de dezembro de 2015 por organizações indígenas do estado de Roraima. Essa representação revela a força dessa população no que diz respeito à supervisão e ao acompanhamento das políticas públicas voltadas ao interesse coletivo dos povos indígenas. 
O quadro de servidores do CEFORR é composto por docentes do quadro efetivo da união, do estado e cargos comissionados. Esses profissionais são habilitados nas mais diversas áreas do conhecimento. Atualmente, o curso conta com 42 professores formadores.

Os cursos para a formação inicial de professores indígenas são os magistérios Tamîkan, Amooko lisantan e Yarapiari, ofertados em nível fundamental e médio. Além desses, o CEFORR oferta a formação continuada Murumurutá, voltada ao ensino da língua materna das etnias atendidas.

O curso Tamîkan[5], que traduzido do Macuxi para o português significa "sete estrelas", é realizado no período de recesso escolar indígena, considerando que os alunos já atuam como docentes em suas comunidades. Esse curso capacita professores das etnias Macuxi, Sapará, Taurepang, Wapichana, Waiwai, Yecuana, Ingaricó e formou 138 (cento e trinta e oito) professores no mês de setembro de 2018. É importante destacar que, diferentemente dos professores não indígenas, esses não gozam férias, pois tal período é destinado para a sua formação.

O referido curso é realizado com a parceria de diversas outras instituições, como a Fundação Nacional do Índio (FUNAI), a Fundação Nacional de Saúde (FUNASA), o Instituto Insikiran da Universidade Federal de Roraima (UFRR), e organizações indígenas, como a Organização do Professores Indígenas de Roraima (OPIRR), o Conselho Indígena de Roraima ( $\mathrm{CIR}$ ), a Organização das Mulheres Indígenas de Roraima (OMIR), a Associação dos Povos Indígenas de Roraima (APIRR), a Aliança de Integração e Desenvolvimento das Comunidades Indígenas de Roraima (ALIDICIR), a Associação dos Povos Indígenas da Terra de São Marcos (APITSM), o Conselho dos Professores Indígenas do Amazonas (COPIAM), o Conselho dos Povos Indígenas Ingarikó (COPING), a Associação Yanomami (HAY HUTUKARA), a Sociedade de Defesa dos Índios do Norte de Roraima (SODIUR) e a Associação dos Povos Indígenas Taurepang, Wapichana e Macuxi (TWM), conforme apresentado no Projeto do curso Tamî'kan Roraima (2011). 
Referente ao currículo, o Projeto Político Pedagógico do Magistério Tamî'kan, quanto à metodologia e organização do tempo do curso, apresenta que:

O currículo manterá uma flexibilidade de acordo com as necessidades da prática pedagógica do professor indígena (cursista). Nesta perspectiva o curso se desenvolverá a partir de temas-contextuais, que são relevantes na realidade em que, o professor indígena (cursista) se insere. Portanto, estes temas serão apresentados no início do curso e poderão sofrer modificações, sugestões, etc. Assim a metodologia requer uma mudança na concepção de tempo/espaço do curso e da função do professor-formador. A estrutura do curso será organizada na forma de etapas. O papel do professor é o de orientador das investigações realizadas pelo professor indígena (cursista). (RORAIMA, 2011, p. 28).

Como se pode observar, são trabalhados, no curso, temas-contextuais - relevantes à realidade desse estudante - e que representam os eixos de formação. Quanto à estrutura curricular, essa apresenta uma flexibilidade visando a uma construção coletiva, de modo a possibilitar que o estudante indígena seja ativamente envolvido no processo de decisões, inclusive no âmbito curricular. De acordo com Freire (2001, p. 57), "o educando que exercita sua liberdade ficará tão mais livre quanto mais eticamente vá assumindo a responsabilidade de suas ações", nesse sentido, a participação ativa no processo de construção da educação dos indígenas reforça para uma educação autônoma, onde sua participação nesse processo o tornará mais livre e mais ético.

O Curso de Magistério Amooko lisantan[6], de Nível Médio e Profissionalizante, teve início em 2013 e é ofertado, especificamente, aos povos Ingaricó, Macuxi e Patamona[7], teve seu projeto construído nas assembleias gerais dos povos Ingaricó e do Conselho do Povo Indígena Ingaricó (COPING). Visa a formar professores para atuarem na Educação Infantil e anos iniciais do Ensino Fundamental. Trata-se de uma formação intercultural, com o compromisso de contribuir na "autonomia e o 
fortalecimento político-cultural dos povos Ingarikó, Macuxi e Patamona" (RORAIMA, 2018, p. 13).

A atuação nesse curso se dá de maneira multilinguística, pois atende aos falantes das línguas Ingaricó, Macuxi e Patamona. Dessa forma, os textos são traduzidos para as três línguas, que não têm muita semelhança entre si. O curso conta com uma equipe composta por linguistas, antropólogos, sociólogos e pedagogos, além da atuação ativa dos professores de tais etnias. A língua portuguesa também é ensinada nesse curso, a fim de possibilitar a aptidão para se comunicarem com os falantes desta.

O Curso Magistério Yarapiari, que traduzido do Yanomami para o português quer dizer "espírito do sabiá", capacita indígenas da etnia Yanomami, que já atuam como docentes, porém não possuem formação.

Trata-se de um curso de nível médio e profissionalizante e teve sua origem na Comissão Pró-Yanomami (CCPY). A formação, iniciada oficialmente em 2001, foi desenvolvida pelo Instituto Socioambiental (ISA), em parceria com Hutukara Associação Yanomami (HAY). A partir de 2010, o CEFORR passou a ser responsável por esse curso de formação, devido à necessidade de organização administrativa para fins de receber fomento por parte do Ministério da Educação (RORAIMA, 2016).

Mesmo assim o curso continua sendo executado pelo Programa de Educação Intercultural[8] (PEI), que teve início em 1995, criado pela CCPY, que passou a fomentar a formação escolar bilíngue visando a manter a língua yanomami e, ao mesmo tempo, oferecer acesso aos conhecimentos produzidos pela humanidade.

O curso também conta com a parceria da OPIRR, CIR, APIRR e a Rede de Cooperação Alternativa (RCA) e recebe fomento da FUNAI, MEC e SEED/RR, além de alguns parceiros internacionais como Rainforest Foundation Noruega (RFN), Estudantes Noruegueses (OD) e Ministério das Relações Exteriores da França (MAE).

Conforme o Projeto Político Pedagógico, o curso de Magistério Yarapiari atua nas regiões de Demini (Toototopi, Parawau, Papiu, Kayanau, Homoxi e Alto Catrimani), onde estão localizados dois terços dos professores que participaram da formação; 
posteriormente ampliou-se para a região de Auaris. A formação também é multilinguística, contando com 05 línguas yanomami, que são: sanöma, yanomae, yanomama, yanomami e yanomami, além da língua portuguesa (RORAIMA, 2016).

Ressaltamos que todos os professores que participam desse curso foram indicados por suas comunidades e, conforme o Projeto Político Pedagógico do curso (RORAIMA, 2016), todos exercem ativamente o magistério e a maioria dos professores tem entre 20 e 30 anos. As escolas Yanomami são de difícil acesso, sendo possível apenas por via aérea. A maior parte dessas comunidades comunicase apenas em sua língua materna e não domina a língua portuguesa.

O objetivo do curso é promover "[...] o exercício da cidadania [...] curso específico e diferenciado [...] docentes Yanomami capazes de desenvolver escolas Yanomami multilíngues [...] com subsídios didáticos próprios” (RORAIMA, 2016, p. 29).

O curso é desenvolvido nas seguintes situações de ensino e aprendizagem: as etapas intensivas, que são presenciais; o aproveitamento de experiência e acompanhamento pedagógico, etapas não presenciais; o intercâmbio com outras escolas indígenas, além da etapa denominada pesquisa, que acontece nas formas presencial e não presencial.

A equipe de formação é composta por uma equipe de assessores da CCPY falantes da língua yanomai e os consultores, que são especialistas de diversas áreas do conhecimento e que ministram as etapas intensivas. O planejamento para as atividades é realizado em conjunto.

As etapas intensivas acontecem em torno de um tema considerado relevante para a comunidade; busca-se a metodologia adequada para abordá-los. Além disso, são produzidos materiais didáticos sobre os temas, como textos, ilustrações e atividades.

O curso conta com carga horária de 5.365 horas/aula. Durante o período do estágio, os professores em formação são acompanhados por um assessor pedagógico, que fica na escola observando a atuação entre 07 e 10 dias, o que geralmente envolve assistir as aulas e conversar com membros da comunidade e alunos, para conhecer 
o trabalho do professor em formação e as questões relacionadas à escola. Juntamente com as lideranças locais, são organizadas reuniões com o professor em formação para avaliá-lo e orientá-lo visando à melhoria do ensino e da aprendizagem naquela escola. Entre 2001 a 2009, após 15 etapas intensivas, formou-se a primeira turma de professores Yanomami.

O Curso de Capacitação e Formação Continuada de Professores Indígenas Murumurutá, que significa "pássaro" na língua Macuxi, é voltado para professores da rede estadual de ensino que ministram a disciplina de Língua Materna Indígena em suas escolas, línguas essas dos povos Macuxi, Wapixana, Taurepang e Ingarikó. O curso tem carga horária de 200 horas, e capacita professores indígenas de oito dos quinze municípios do estado: Alto Alegre, Amajari, Normandia, Boa Vista, Cantá, Uiramutã, Bonfim e Pacaraima.

A formação, assim como as demais aqui mencionadas, busca a valorização da língua materna indígena e o diálogo intercultural. Tem por objetivo habilitá-los com um curso de linguística "para serem multiplicadores do conhecimento adquirido junto aos demais professores de Língua Materna Indígena e para o exercício da docência" (RORAIMA, 2017, p. 10).

O curso nasceu para atender à reinvindicação de pais, professores, gestores das escolas e lideranças indígenas e é realizado em parceria com a FUNAI, FUNASA, Instituto Insikiran/UFRR, além das organizações indígenas OPIRR, CIR, OMIR, APIRR, ALIDICIR, APITSM, COPIAM, COPING, HAY HUTUKARA, SODIUR e TWM.

O conhecimento produzido a partir dos cursos ofertados pelo CEFORR, está para além de uma educação pautada na manutenção das tradições e costumes, busca-se construir um modelo de educação escolarizada, que atenda às especificidades dos grupos indígenas e que valorize sua cultura. Ou seja, a formação dos professores não está voltada somente para o objetivo de manter e fortalecer sua língua e sua cultura, mas sim que possam ser capazes de assimilar os conhecimentos científicos e os relacionarem aos seus saberes tradicionais. Destacamos que cada curso atende somente às comunidades especificadas. 
A formação de professores proporcionada pelo CEFORR busca na dimensão pedagógica, viabilizar a criação ou mesmo a ressignificação de novas práticas pedagógicas capazes de acompanhar as demandas contemporâneas da sociedade. Na dimensão política, sua função é libertar o sujeito mediante novos conhecimentos, viabilizando a autonomia desses professores e, consequentemente, de seus alunos.

Observa-se, portanto, que essas ações de formação para professores indígenas cumprem as funções políticas e pedagógicas, relevantes enquanto política educacional e de formação, uma vez que o Estado tem por obrigação realizar a oferta e os povos indígenas têm o direito ao acesso a essa formação. Nessa perspectiva, observa-se que os cursos atendem ao respeito e a valorização da cultura dos povos indígenas, dos seus valores, das suas identidades, da sua língua, e possibilitam a troca de experiências entre as etnias, favorecendo o respeito à diversidade, assim como o respeito mútuo e o fortalecimento identitário, aproximando-se de uma pedagogia crítica e emancipadora.

Vale destacar que todo o arcabouço de garantias legais apresentado enfatiza que a educação escolar indígena deve ser diferenciada, alicerçada por práticas interculturais e bilíngues, encaminhamentos esses atendidos pelos Projetos Políticos Pedagógicos dos cursos ofertados pelo CEFORR e apresentados neste artigo.

É importante destacar que em Roraima outras instituições promovem a formação de professores indígenas em âmbito federal, como o Instituto Insikiran, localizado na Universidade Federal de Roraima (UFRR), no Campus Paricarana, em Boa Vista, e também o Instituto Federal de Roraima (IFRR). Aqui, apresentaremos sucintamente as duas instituições, uma vez o enfoque principal do nosso estudo é a formação proporcionada aos professores indígenas pelo CEFORR.

Segundo Freitas e Torres (2013), o Instituto Insikiran de Formação Superior Indígena da Universidade Federal de Roraima (UFRR) foi criado em 2001, atendendo às reivindicações da Organização dos Professores Indígenas de Roraima (OPIRR). O instituto realiza diferentes tipos de ações afirmativas voltadas a estudantes indígenas, e todos os cursos são destinados à população indígena. Alguns projetos são 
inovadores, como o Curso de Licenciatura Intercultural, que possibilita a formação intercultural para professores indígenas, o bacharelado em Gestão Territorial Indígena, criado em 2009, e que forma gestores indígenas, bem como o Curso de Gestão em Saúde Coletiva Indígena, criado em 2012. Consideram os autores tais iniciativas pioneiras entre as Universidades Federais, sendo a UFRR a primeira universidade a garantir a formação de profissionais indígenas para gerir seus territórios, por meio do Ensino Superior.

O Instituto Federal de Roraima (IFRR), por sua vez, atua em duas frentes de políticas públicas educacionais para a formação dos povos indígenas. A primeira consiste no Programa Ação Saberes Indígenas na Escola, que objetiva promover a formação continuada dos professores da educação escolar indígena. Em 2015, foi firmado um Termo de Cooperação Interinstitucional entre o IFRR, a Universidade Estadual de Roraima (UERR) e a UFRR, com o objetivo de promover e favorecer a colaboração entre as instituições para a execução e operacionalização das atividades desse programa (BRASIL, 2015).

Segundo a Coordenadora do IFRR, aproximadamente 600 professores foram capacitados pelo programa no período de 2014 a 2018, a partir dessa parceria interinstitucional, com formação inicial e continuada. Trata-se de uma política pública que foi financiada pela extinta SECADI/MEC. Ainda se aguardam os próximos direcionamentos para o referido programa, em face da nova estrutura organizacional do MEC.

A segunda trata-se do Comitê Gestor de Políticas para a Educação Escolar Indígena, que surgiu a partir de demandas advindas das Comunidades Indígenas que requeriam formação técnica aos seus povos, processo de articulação iniciado em 2013, momento em que acontecia, na Terra Indígena Raposa Serra do Sol, um programa institucional que ofertou, conforme o Histórico de criação e atuação do Comitê Gestor de Políticas para a Educação Escolar Indígena, Brasil (2018), "cursos de formação inicial em áreas de informática, gestão de turismo, sustentabilidade, gestão ambiental, educação, dentre outras áreas demandadas por Comunidades da etnia Ingarikó". 
Esse comitê foi institucionalizado pelo IFRR em 2015 e, dentre as ações até então desenvolvidas para os povos indígenas em Roraima, realizou levantamento de demandas de cursos a distância; participou de assembleias gerais e regionais do CIR, OPIRR, OMIRR e COPING; realizou acompanhamentos em cursos de extensão; contribuiu com a elaboração de Projetos Políticos Pedagógicos de escolas indígenas; contribuiu com o desenvolvimento de diversos cursos para a formação continuada de professores realizadas por meio do Programa Ação Saberes Indígenas na Escola, além de acompanhar o desenvolvimento de Cursos de Formação Inicial e Continuada (FIC), voltados para esse público.

Percebemos, assim, a força dos povos indígenas para a consolidação de políticas públicas voltadas para o estabelecimento de seus direitos e para a garantia desses. A educação é direito de todos e dever do Estado e da família, estabelecido assim pela Constituição Federal/1988. Os povos indígenas têm assegurado o direito a uma educação diferenciada, intercultural e bilíngue, conforme retratado por diversas legislações. Todavia, importa destacar que, embora já existam políticas educacionais para a formação dos povos indígenas em Roraima, esta necessita de ampliação e consolidação.

\section{CONSIDERAÇÕES FINAIS}

O processo de expansão e democratização do ensino no Brasil aconteceu de modo tardio, tendo permanecido por quase quatro séculos uma educação totalmente aristocrática. Nas primeiras décadas do século XX, marcada pelo processo de industrialização do país, a educação seguiu os mesmos moldes do ensino tradicional e a camada popular, assim como os povos indígenas, não tinham espaço na elaboração da legislação educacional, ficando a cargo dos grupos dominantes definir o currículo escolar, que não prezava pela valorização da diversidade cultural do país, mas sim pela manutenção da estrutura social.

O reconhecimento da diversidade sociocultural dos povos indígenas garantido a partir da Resolução CEB/CNE no 3 de 1999, representou um grande avanço para a educação escolar indígena visto que, por séculos, se buscou a padronização do 
ensino através da imposição curricular que ignorava as especificidades dos povos. A diversidade étnica e cultural desses povos, que possuem práticas específicas, mostra que não se pode criar um único modelo de escola indígena e implantá-lo, é preciso respeitar a identidade cultural, histórica e linguística de todos os povos.

Dessa forma, a capacitação de professores indígenas é extremamente importante, pois assegura o fortalecimento das práticas socioculturais e da língua materna desses povos, sendo de extrema importância também a participação da comunidade na elaboração de metodologias de ensino-aprendizagem que estejam em consonância com os interesses da mesma.

A partir desta pesquisa, compreendemos que a formação oferecida pelo CEFORR para a formação de professores indígenas iniciou após um processo de reivindicação desses povos. Essa formação não é prestada apenas pelos professores formadores vinculados ao CEFORR, ela é realizada em cooperação com instituições governamentais ligadas a questões indígenas, e também em colaboração com as diversas organizações dos povos indígenas do estado de Roraima.

Percebemos que os povos indígenas são extremamente organizados e ativos no tocante ao exercício da cidadania e à luta pela garantia dos seus direitos. Reivindicando e cobrando políticas públicas que venham salvaguardar sua língua, sua cultura, sua terra, unem-se ainda mais quando a pauta gira em torno de questões inerentes à saúde e educação.

Vimos que no estado de Roraima outras instituições oferecem cursos de formação para professores indígenas, sendo que este artigo deu destaque ao CEFORR, que tem ofertado quatro cursos voltados para esse público, três deles de nível médio técnico (magistério indígena) e um de formação continuada, todos visando à valorização da língua materna e o diálogo intercultural. Esses cursos permitem a formação de professores das etnias Macuxi, Sapará, Taurepang, Wapichana, Waiwai, Yecuana, Ingaricó, Patamona e Yanomami. 
A oferta de cursos de formação inicial e continuada pelo CEFORR para a capacitação e qualificação dos professores indígenas do estado de Roraima é de grande relevância e atende ao que recomendam as legislações. No entanto, essa não é a única necessidade emergencial da educação escolar indígena.

Dentre as fragilidades dessas escolas, questões referentes à infraestrutura interferem diretamente na qualidade do ensino, pois os professores indígenas atuam em escolas improvisadas, com ausência de biblioteca, sem o fornecimento regular de merenda escolar, com material didático inadequado, escasso e, muitas vezes, inexistente, esses são apenas alguns pontos que requer providências por parte do Estado.

Apesar da Resolução CEB/CNE no 3 de 1999 garantir que o ensino seja ministrado na língua materna, ainda é muito comum nas escolas indígenas do estado de Roraima encontrar professores ministrando aula em português e utilizando os mesmos métodos e conteúdo das escolas não indígenas, o que demonstra uma necessidade de que seja objeto de estudo o currículo dos cursos de formação para professores indígenas proporcionados pelas instituições formadoras.

Além disso, é possível encontrar em algumas escolas indígenas professores indígenas não falantes de língua indígena materna e, portanto, não contribuem para o fortalecimento da língua de sua etnia. Tal fato demonstra uma carência de professores capacitados para atuar em suas comunidades realizando um resgate linguístico a fim de manter uma parte importante da cultura dos povos indígenas, sua própria língua.

O desafio atual, porém, está na verticalização da formação, que possa especializar esses professores indígenas a partir da continuidade da formação acadêmica, com cursos de especialização, mestrados e doutorados voltados para a formação específica dos povos indígenas.

Para isso, deve-se garantir a formação inicial de todos os professores que atuam nas escolas indígenas. Daí a importância da ampliação da oferta de cursos de formação às populações indígenas, dada a predominância das escolas indígenas em Roraima, 
levando em consideração o elevado número de comunidades indígenas espalhadas pelo estado, com diferentes necessidades e culturas diversificadas.

Por fim, não podemos deixar de fazer referência ao cenário de incertezas para a população indígena frente às políticas do atual governo, a exemplo da (não obstante suspensa pelo Supremo Tribunal Federal) Medida Provisória ㄲo 886, de 2019, que transfere a responsabilidade das demarcações de terras indígenas, outrora atribuição da Fundação Nacional do Índio (FUNAI), para o Ministério da Agricultura, Pecuária e Abastecimento (MAPA), cuja ministra foi indicada pela bancada ruralista do Congresso. Contudo conhecendo a força e organização dos povos indígenas, em especial do estado de Roraima, podemos inferir que a luta continuará.

\section{REFERÊNCIAS}

ABBONIZIO, Aline; GHANEM, Elie. Educação escolar indígena e projetos comunitários de futuro. Revista Educação e Pesquisa, v. 42, n. 4, p. 887-901, out./dez., São Paulo: 2016.

BRASIL. Decreto no 8.072, de 20 de junho de 1910. Crêa o Serviço de Protecção aos Indios e Localização de Trabalhadores Nacionaes e approva o respectivo regulamento. Rio de Janeiro, RJ: Diário Oficial da União - Seção 1 - 26/6/1910, Página 4869 (Republicação). Disponível em <https://bit.ly/31M5Om3>. Acesso em 19 de junho de 2019.

. Lei no 5.371, de 5 de dezembro de 1967. Autoriza a instituição da "Fundação Nacional do Índio" e dá outras providências. Brasília, DF: Diário Oficial da União. Seção 1. Retificado em 12/12/1967. p. 12447. Disponível em <http://www.planalto.gov.br/ccivil_03/leis/1950-1969/L5371.htm>. Acesso em 19 de junho de 2019.

. Lei oㅡ 6.001, de 19 de dezembro de 1973. Dispõe sobre o Estatuto do Índio.

Diário Oficial da República Federativa do Brasil. Disponível em 
$<$ http://www.planalto.gov.br/ccivil_03/leis/l6001.htm>. Acesso em 25 de outubro de 2018.

. Constituição (1988). Constituição da República Federativa Do Brasil. Brasília, DF: Senado Federal: Centro Gráfico. 1988.

. Decreto Presidencial o 26, de 04 de fevereiro de 1991. Dispõe sobre a educação indígena no Brasil. Diário Oficial [da] República Federativa do Brasil. Disponível em <http://www2.camara.leg.br>. Acesso em 17 de setembro de 2018.

. MEC. Diretrizes para a Política Nacional de Educação Escolar Indígena. Brasília: MEC/SEF, 1993. 22 p.

. MEC. Lei oํ 9.394, de 20 de dezembro de 1996. Estabelece as diretrizes e bases da educação nacional. Brasília: MEC. 1996. Disponível em <http://www.planalto.gov.br/ccivil_03/leis/19394.htm>. Acesso em 25 de outubro de 2018.

. MEC. Secretaria de Educação Fundamental, Departamento de Política da Educação Fundamental, Coordenação Geral de Apoio às Escolas Indígenas. O Governo Brasileiro e a Educação Escolar Indígena. Brasília, 1998.

. Referencial Curricular Nacional para as Escolas Indígenas. Ministério da Educação, Secretaria de Educação fundamental. Brasília: MEC/SEF, 1998.

. Parecer CEB/CNE no 14, de 14 de setembro de 1999. Diretrizes Curriculares Nacionais da Educação Escolar Indígena. MEC/CEB/CNE. Disponível em <http://portal.mec.gov.br/cne/arquivos/pdf/1999/pceb014_99.pdf>. Acesso em 25 de outubro de 2018.

Resolução CEB/CNE № 3, de 10 de novembro de 1999. Fixa Diretrizes Nacionais para o funcionamento das escolas indígenas e dá outras providências. $\mathrm{MEC} / \mathrm{CEB} / \mathrm{CNE}$. Disponível em 
$<$ http://portal.mec.gov.br/cne/arquivos/pdf/rceb03_99.pdf>. Acesso em 17 de setembro de 2018.

. MEC. Referenciais para a formação de professores indígenas. Brasília: MEC/SEF, 2002. $83 \mathrm{p}$.

. Decreto o 5.051 de 19 de abril de 2004. Promulga a Convenção no 169 da Organização Internacional do Trabalho - OIT sobre Povos Indígenas e Tribais: Diário Oficial da República Federativa do Brasil. Brasília, 2004. Disponível em <http://www.planalto.gov.br/ccivil_03/_ato2004-2006/2004/decreto/d5051.htm>. Acesso em 25 de outubro de 2018.

Planejando a próxima década: Conhecendo as 20 metas do plano nacional de educação. Ministério da Educação / Secretaria de Articulação com os Sistemas de Ensino (MEC/ SASE), 2014. Disponível em <http://pne.mec.gov.br>. Acesso em 17 de setembro de 2018.

. Lei oㅜ 13.005 de 25 de junho de 2014. Aprova o Plano Nacional de Educação - PNE e dá outras providências. Diário Oficial da República Federativa do Brasil. Brasília, 2014. Disponível em <http://www.planalto.gov.br/ccivil_03/_ato20112014/2014/lei//13005.htm>. Acesso em 25 de outubro de 2018.

Acordo de Cooperação no 07/2015. Acordo de Cooperação Técnica, Administrativa, Científica e Pedagógica que celebram entre si o Instituto Federal de Roraima, a Universidade Estadual de Roraima e a Universidade Federal de Roraima. IFRR. Boa Vista, RR: 2015.

. Medida Provisória n 886, 18 de junho de 2019. Diário oficial da República Federativa do Brasil, Poder Executivo. Brasília, DF, Publicado em: 19/06/2019 Edição: 117 | Seção: 1 | Página: 2. Disponível em <http://www.in.gov.br/en/web/dou//medida-provisoria-n-886-de-18-de-junho-de-2019-164324640>. Acesso em 25 de junho de 2019. 
CANDAU. Vera Maria. Multiculturalismo e educação: desafios para a prática pedagógica. In: Multiculturalismo: diferenças culturais e práticas pedagógicas / Antônio Flávio Moreira, Vera Maria Candau (orgs.). 2. ed. - Petrópolis, RJ: Vozes, 2008.

DAVID, Moisés; MELO, Maria Lúcia; MALHEIRO, João Manoel da Silva. Desafios do currículo multicultural na educação superior para indígenas. Revista Educação e Pesquisa, v. 39, n. 1, p. 111-125, jan./mar. São Paulo: 2013.

FREIRE, Paulo. Pedagogia da autonomia: saberes necessários à prática educativa. 20 ed. São Paulo: Paz e Terra, 2001.

FREITAS, Antonio Braga de; TORRES, Iraildes Caldas. Diálogos Interculturais no Contexto da Formação de Professores Indígenas. IV Reunião Equatorial de Antropologia e XIII Reunião de Antropólogos do Norte e Nordeste, 04 a 07 de agosto de 2013. Fortaleza-CE. Disponível em $<$ http://www.reaabanne2013.com.br/anaisadmin/uploads/trabalhos/7 trabalho 00057 2 1373579927.pdf>. Acesso em 24 de setembro de 2018.

GRUPIONI, Luís Donisete Benzi. Quando a antropologia se defronta com a educação: formação de professores índios no Brasil. Revista PRO-POSIÇÕES, v. 24, n. 2 (71), p. 69-80, mai./agos. São Paulo: 2013.

HISTÓRICO de criação e atuação do Comitê Gestor de Políticas para a Educação Escolar Indígena. IFRR. Boa Vista, RR, 2018.

IBGE. Instituto Brasileiro de Geografia e Estatística. Os Indígenas no Censo Demográfico 2010. Brasília: IBGE, 2010. Disponível em $<$ https://indigenas.ibge.gov.br/ images/indigenas/estudos/indígena $>$. Acesso em 17 de setembro de 2018.

INEP. Censo escolar 2018. Ministério da Educação. INEP - Instituto de Nacional de Estudos e Pesquisas Educacionais Anísio Teixeira. Disponível em 
<http://portal.inep.gov.br/web/guest/resultados-e-resumos>. Acesso em 15 de setembro de 2019.

RORAIMA. Lei № 1.008 de 03 de setembro de 2015. Plano Estadual de Educação 2014/2024 (PEE) e dá outras providências. Assembleia Legislativa de Roraima. Disponível em $\quad<$ http://leis.al.rr.leg.br/leis/leis-ordinarias/viewcategory/792015?start=10 >. Acesso em 17 de setembro de 2018.

. Parecer no 19 CE/CEE/CP, de 25 de maio de 2004. Projeto Tamîkan, Magistério Indígena. Conselho Estadual de Educação de Roraima/SEED. Boa Vista: CEE, 2004. 05 p.

. Projeto "Murumurutá" de Línguas Indígenas. Secretaria de Educação e Desportos (SEED). Boa Vista: Centro Estadual de Formação dos Profissionais da Educação de Roraima (CEFORR), 2017.

. Projeto Magistério Indígena Amooko lisantan. Secretaria de Educação e Desportos (SEED). Boa Vista: Centro Estadual de Formação dos Profissionais da Educação de Roraima (CEFORR), 2018.

. Projeto Político Pedagógico do Magistério Indígena Tamîkan. Secretaria de Educação e Desportos (SEED). Boa Vista: Centro Estadual de Formação dos Profissionais da Educação de Roraima (CEFORR), 2011.

- Projeto Político Pedagógico do Magistério Yarapiari. Formação de professores Yanomami. Secretaria de Educação e Desportos (SEED). Boa Vista: Centro Estadual de Formação dos Profissionais da Educação de Roraima (CEFORR), 2016.

SANTOS, Raimundo Nonato Gomes dos. Cultural política e relação intercultural: indígenas e não indígenas na história de Roraima. In: ARANTES et al. Amazônia: espaço, cultura e visões de mundo. Boa Vista: Editora da UFRR, 2009. p.104-131. 
SILVA, Rosa Helena Dias da. A autonomia como valor e articulação de possibilidades: O movimento dos professores indígenas do Amazonas, de Roraima e do Acre e a construção de uma política de educação escolar indígena. Cadernos Cedes, ano XIX, no 49, Dezembro, Campinas, 1999.

SOUZA, Ana Hilda Carvalho de. Sustentabilidade Sociocultural de Indígenas em área urbana. 2016. $301 \mathrm{f}$. Tese. Doutorado em Ambiente e Desenvolvimento. CENTRO UNIVERSITÁRIO UNIVATES. Lajeado: 2016.

\section{APÊNDICE - REFERÊNCIAS DE NOTA DE RODAPÉ}

5. O Projeto Magistério Indígena Tamî'kan é um curso profissionalizante orientado para oferecer aos professores indígenas alunos(as) formação específica bilíngue (multilíngue) e intercultural, concebido em uma plataforma curricular correspondente ao Ensino Médio e complementação com disciplinas específicas na Formação de Magistério Indígena. Tamî'kan na língua Macuxi significa: sete estrelas, o tempo chuvoso, o tempo promissor.

6. Amooko lisantan é uma homenagem a um líder da Comunidade Indígena Serra do Sol, o primeiro a defender o seu território.

7. É importante frisar que foi a primeira vez que a etnia Patamona teve acesso a uma formação com representatividade e sendo reconhecido como um povo.

8. O PEl teve início na comunidade Demini em 1995, como projeto piloto. A formação de professores iniciou-se em 2001, capacitando também assessores pedagógicos, além de produzir diversos materiais didáticos para as escolas Yanomami.

Enviado: Fevereiro, 2020.

Aprovado: Fevereiro, 2020. 